\title{
PEMANFAATAN TEKNOLOGI INFORMASI MENGGUNAKAN APLIKASI EDMODO UNTUK GURU DAN SISWA SEBAGAI MEDIA PEMBELAJARAN PADA SMK MUHAMMADIYAH 4 AL-AMIN BANJARMASIN
}

\author{
Auliya Rahman, Budi Setiadi, Dian Agustini, dan Muthia Farida
}

Fakultas Teknologi Informasi, Universitas Islam Kalimantan

Email : auliyarahmankom@gmail.com

\begin{abstract}
ABSTRAK
SMK Muhammadiyah 4 Al-Amin Banjarmasin adalah salah satu sekolah swasta yang berada di kota Banjarmasin yang mempunyai 2 program keahlian yaitu teknik komputer jaringan dan teknik kendaraan ringan. Seiring kemajuan zaman yang selalu berkembang, keterampilan pembelajaran dan pendidikan telah mengalami banyak perubahan. Di tempat ini dalam belajar mengajar untuk siswa masih mengalami kekurangan dalam bidang penerapan teknologi informasi, maka dari itu mengadakan pengabdian kepada masyarakat sangat tepat untuk memberikan pelatihan tentang belajar mengajar secara online menggunakan aplikasi Edmodo kepada tenaga pengajar atau guru, apalagi sekarang ini terjadi situasi pandemik covid 19 yang mengharuskan semua orang khususnya guru dan siswa aga belajar mengajar dirumah. Aplikasi ini juga bisa untuk berbagi ilmu, pengumpulan tugas dan lain-lain. Saat ini, metode belajar mengajar baik ujian, pengumpulan tugas dan lain-lain hanya menggunakan cara konvensional, masih belum menggunakan media internet atau secara online. Tujuan nya untuk mengikuti perkembangan zaman dan membuat cara belajar mengajar lebih interaktif dan lebih menarik baik untuk tenaga pengajar atau guru dan siswa bahkan bisa untuk orang tua dari siswa. Manfaat nya adalah untuk memberikan kemudahan dalam belajar mengajar. Hasil yang ingin dicapai agar ikut serta dalam peningkatan dan pemanfaatan teknologi informasi dalam belajar mengajar agar lebih efektif dan efisien.
\end{abstract}

\section{Kata kunci : Media Pembelajaran, Edmodo}

\section{PENDAHULUAN}

Mitra dalam pengabdian kepada masyarakat ini adalah SMK Muhammadiyah $\quad 4 \quad$ Al-Amin Banjarmasin beralamat Jl. Gerilya No.10 RT.18 Tanjung Pagar, Tanjung Pagar, Kec. Banjarmasin Selatan, Kota Banjarmasin. Saat ini sepertinya perangkat komputer khususnya software atau perangat lunak serta berbagai aplikasinya sudah tidak asing lagi di kalangan masyarakat indonesia, khususnya kalimantan selatan baik dari kalangan atas hingga menengah kebawah, dari bidang akademisi, kedokteran, bisnis hingga desain grafis atau multimedia. Perkembangan penggunaan media komputer saat ini pun begitu pesat baik perangkat keras maupun perangkat lunaknya. Salah satunya dalam bidang belajar mengajar secara online yaitu aplikasi Edmodo 
yang bisa digunakan dengan sistem operasi android dan Personal Komputer Sistem Operasi Windows (Erwanto. (2015). Namun, seiring dengan maraknya teknologi informasi saat ini masih banyak yang belum bisa menggunakan beberapa aplikasi komputer, padahal melihat situasi sekarang ini indonesia dilanda pandemic covid- 19, dimana semua orang diharuskan bekerja dari rumah, dalam hal ini belajar mengajar antara guru dan siswa sangat tergantung pada aplikasi komputer salah satunya Aplikasi Edmodo. Edmodo adalah perusahaan teknologi pendidikan yang menawarkan alat komunikasi, kolaborasi, dan pembinaan untuk guru dan siswa yang memungkinkan guru berbagi konten, mendistribusikan kuis, tugas, melaksanakan ujian secara online dan mengelola komunikasi dengan siswa dan orang tua. Dari sudut pandang siswa, ketegangan saat mengerjakan soal-soal UN pasti akan bertambah karena beberapa kekurang nyamanan yang diakibatkan penggunaan komputer. Namun semua kekurang nyamanan sistem berbasis komputer akan dapat dikurangi dengan latihan, sehingga siswa terbiasa dan memahami tips yang benar dalam mengerjakan ujiannya (Herri Sulaiman, 2020).

Sebagai wujud ikut serta dalam mencerdaskan bangsa, maka pada kegiatan pengabdian kepada masyarakat kali ini mengadakan Pemanfaatan Teknologi Informasi Menggunakan Aplikasi Edmodo Untuk Guru dan Siswa Sebagai Media Pembelajaran Pada Smk Muhammadiyah 4 Al-Amin Banjarmasin, dengan harapan adanya peningkatan dan keterampilan dalam belajar mengajar secara online, guru dan siswa dapat lebih optimal dalam memanfaatkan teknologi informasi saat ini. Teknologi informasi dan komunkasi (TIK) sebagai sarana pendukung pembelajaran di sekolah dalam rangka untuk meningkatkan kualitas proses belajar mengajar dan sebagai penunjang kompetensi guru ( Agus Alim Muin, 2019)

Pada pengabdian kepada masyarakat ini diajarkan bagaimana cara menjalankan aplikasi Edmodo seperti menggunakan tools yang ada di dalam aplikasi, membuat konten yang akan disajikan secara menarik sehingga siswa akan mudah untuk memahaminya dan dapat diterapkan pada kegiatan belajar mengajar sehari-hari (Pratama R, M. D., \& Subroto, W.T, 2017) 


\section{METODE}

Untuk menunjang Pemanfaatan Teknologi Informasi Menggunakan Aplikasi Edmodo Untuk Guru dan Siswa Sebagai Media Pembelajaran Pada SMK Muhammadiyah 4 Al-Amin Banjarmasin, maka digunakan pendekatan melalui pelatihan secara daring atau online menggunakan google meet. Melalui pelatihan online ini peserta dilatih oleh instruktur dan dengan materi pelatihan sebagai berikut

1. Perkenalan dan penjelasan tentang aplikasi Edmodo secara daring atau online.

2. Tutorial, instruktur menjelaskan tentang aplikasi Edmodo dengan menggunakan power point yang ditampilkan dengan menggunakan google meet.

3. Pemanfaatan modul.

4. Pendalaman materi aplikasi Edmodo.

5. Praktek Mandiri, setiap peserta melakukan praktek berupa proses menggunakan aplikasi Edmodo dengan tools yang ada.

6. Tanya Jawab secara daring dengan google meet.

\section{KHALAYAK SASARAN}

Adapun khalayak sasaran yang ingin dicapai pada kegiatan pengabdian kepada masyarakat ini adalah diperlukan daya saing dalam hal teknologi informasi tak terkecuali bagi guru dan siswa di SMK Muhammadiyah 4 Al-Amin Banjarmasin walaupun dalam situasi pandemik covid 19 ini. Oleh karena itu, perlunya inovasi pengajaran melalui media teknologi informasi mendasari tim untuk memberikan pelatihan bagaimana mengoptimalkan penggunaan teknologi infromasi khususnya aplikasi Edmodo. Pada dasarnya peserta sudah mendapatkan pengajaran tentang teknologi informasi , namun perlunya pendalaman serta inovasi dalam sistem belajar mengajar karena :

1. Membantu peserta mengenal lebih jauh kelebihan-kelebihan yang belum diketahui dalam aplikasi.

2. Meningkatkan daya saing peserta dalam hal dunia teknologi informasi walupun dalam situasi pandemik covid 19 sekarang.

3. Meningkatkan keahlian untuk menghasilkan peserta yang produktif dan interaktif 


\section{HASIL PELAKSANAAN}

KEGIATAN

\section{Hasil Kegiatan}

Hasil pelaksanaan kegiatan

Pemanfaatan Teknologi Informasi

Menggunakan Aplikasi Edmodo Untuk

Guru dan Siswa Sebagai Media

Pembelajaran

Pada SMK

Muhammadiyah

4

Al-Amin

Banjarmasin, adalah sebagai berikut

1. Guru dan siswa peserta pelatihan di SMK Muhammadiyah 4 Al-Amin Banjarmasin ".sebanyak 20 orang dapat menggunakan aplikasi

Edmodo dengan baik dan benar.

2. Meningkatknya kreativitas dan keterampilan guru dan siswa setelah mendapatkan pelatihan secara daring atau online untuk menggunakan aplikasi Edmodo.

3. Guru dan siswa dapat menggunakan tools dengan baik dan benar dalam aplikasi Edmodo.

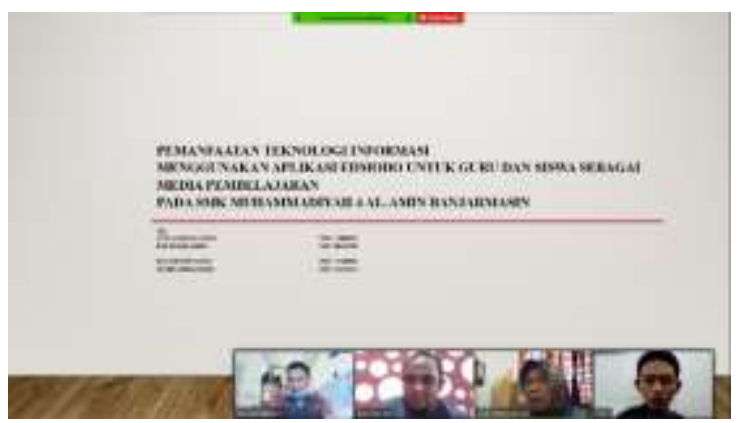

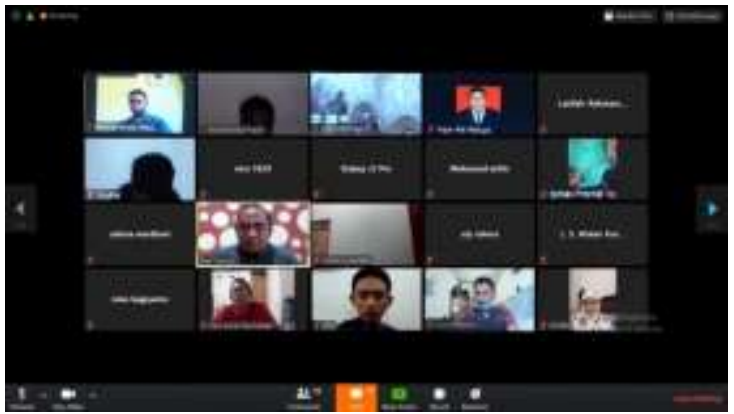

Analisa Terhadap Hasil Yang Di Peroleh

Berdasarkan hasil yang di peroleh dari kegiatan ini adalah antusiasnya guru dan siswa di SMK Muhammadiyah 4 Al-Amin Banjarmasin, saat merespon kegiatan pengabdian kepada masyarakat yang di lakukan, karena sebelum memulai pelatihan kami mengadakan tanya jawab atau kuisioner kepada peserta pelatihan tentang aplikasi Edmodo dan belajar mengajar secara daring, dimana $30 \%$ dari peserta belum mengatahui atau menggunakan aplikasi Edmodo, setelah pelatihan aplikasi edmodo selesai kami mengadakan tanya jawab atau kuisioner kembali dan hasilnya 85 $\%$ guru dan siswa sudah bisa menggunakan aplikasi Edmodo dengan baik dan benar. Harapannya di SMK Muhammadiyah 4 Al-Amin Banjarmasin, tetap menggunakan aplikasi Edmodo dalam hal belajar mengajar apalagi dalam situasi pendemik covid 19 ini. 


\section{Evaluasi kegiatan}

Evaluasi keberhasilan kegiatan pengabdian kepada masyarakat ini di lakukan setelah kegiatan selesai. Indikator keberhasilan kegiatan ini dapat dilihat dari respon positif guru dan siswa berdasarkan persentase $85 \%$ dari tanya jawab atau kuisioner, seperti aktif dalam bertanya dan berhasil dalam menyelesaikan tugas yang diberikan saat mengikuti pelatihan ini.

\section{KESIMPULAN}

Pelatihan ini dapat memberikan ilmu pengetahuan dan keterampilan dasar tentang aplikasi Edmodo bagi guru dan siswa dalam belajar mengajar secara online atau daring dengan baik dan benar serta dapat diterapkan secara langsung dalam situasi pandemik covid 19 ini yang mengharuskan belajar mengajar dirumah.

\section{DAFTAR PUSTAKA}

Arjaka, Sugiyono. 2010. Media Elektronik berbasis Komputer sebagai Media dalam Proses Pembelajaran. Malang

Agus Alim Muin, Sari Kumala, Erfan Karyadiputra (2019), Pkms Peningkatan Kompetensi Guru Dan Pengembangan Perangkat Pembelajaran Berbasis It Guna Menunjang Pelaksanaan Kurikulum 2013 Pada Smp
Negeri 1 Anjir Pasar Desa Anjir Pasar Kota Ii Kec. Anjir Pasar Kab. Batola. Jurnal Pengabdian Al-Ikhlas. Vol.5 No.1, Hal : 7886

Erwanto. (2015). Tutorial Membuat Akun Edmodo Untuk Siswa. https://www.kompasiana.com/er wanbio/tutorial-membuat-akunedmodo untuk siswa_553118b45a2. (Diakses tanggal 13 Desember 2019).

Fahrudin, Eva \& Muhamad Rohmania. (2016). Penerapan Metode ELearning Menggunakan Edmodo Di Smk Gema Bangsa Untuk Meningkatkan Mutu Pembelajaran Di Bidang Iptek. Prosiding Temu Ilmiah Nasional Guru (Ting) Viii, 379-388.

Herri Sulaiman, Trusti Hapsari, Tonah, Dan Fuad Nasir (2020) Simulasi Aplikasi Tryout Ujian Nasional Berbasis Komputer (Unbk) Online Di Sma Kabupaten Cirebon. Jurnal Pengabdian AlIkhlas. Vol.6 No.1, Hal : 138-147

Hamalik, Oemar. 2008. Kurikulum Dan Pembelajaran. Jakarta : Bum Aksara.

Jubllie, 2013. Inspiring Presentation. Jakarta. Kelompok Gramedia, Anggota IKAPI.

Pratama R, M. D., \& Subroto, W.T.(2017). Pengaruh Penggunaan Edmodo Sebagai Media Pembelajaran E-Learning Terhadap Hasil Belajar Siswa Pada Materi Pasar Modal Mata Pelajaran Ekonomi Kelas X SM. Volume 2 Nomer 2 Edisi Yudisium, 1-9.

Sardiman. 2010. Interaksi dan Motivasi Belajar Mengajar. Jakarta : Rajawali Pers. 